\title{
VISÃO DE OVINOCULTORES SOBRE A ATIVIDADE NO PARANÁ E EM SÃO PAULO, É ESTE UM BOM NEGÓCIO? UM ESTUDO DE CASO
}

Bruna Fonseca Matias ${ }^{1}$, Daiane Andreola1 ${ }^{1}$ Fabíola Cristine de Almeida Rego Grecco $^{2}$, Luis Souza de Souza Reis ${ }^{3}$, Luiz Fernando Coelho da Cunha Filho ${ }^{4}$.

${ }_{1}^{1}$ Mestranda em Saúde e Produção Animal da Universidade Pitágoras Unopar (UNOPAR), Arapongas-PR, Brasil. E-mail:bruna_fonseka@hotmail.com 2 Professora Doutora do curso de Medicina Veterinária da UNOPAR, Arapongas-PR, Brasil.

${ }^{3}$ Professor Doutor do curso de Medicina Veterinária da UNOESTE, Presidente Prudente-SP, Brasil.

${ }^{4}$ Professor Doutor do curso de Medicina Veterinária da UNOPAR, Arapongas-PR, Brasil.

Recebido em: 04/10/2019 - Aprovado em: 30/11/2019 - Publicado em: 15/12/2019 DOI: 10.18677/EnciBio_2019B59

\begin{abstract}
O objetivo foi apresentar a ovinocultura e suas potencialidades pela visão dos

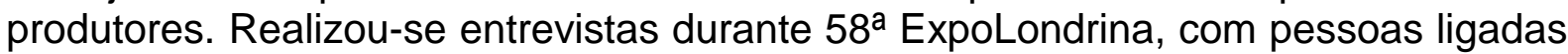
à ovinocultura no estado do Paraná e São Paulo. Buscou-se dados quantitativos do rebanho, motivação para início de criação, participação em eventos, perspectivas da atividade. Entre as propriedades entrevistadas, $51,43 \% \quad(n=18)$ situavam-se no estado de São Paulo e 48,57\% ( $n=17)$ no Paraná. A maioria dos animais presentes no evento possuíam aptidão para genética e carne, visto que em relação à rentabilidade estas duas áreas estão em ápice na criação. Em relação à motivação para iniciar a criação, as respostas variaram entre: negócio, hobby, menor investimento, herança e diversificação de espécies na propriedade. No Paraná cerca de $41,18 \%(n=7)$ criavam por negócio, $29,41 \%(n=5)$ por hobby, $17,65 \%(n=3)$ por herança, $5,88 \%(n=1)$ por ter um menor investimento e 5,88\% $(n=1)$ pela diversificação de espécie. Já em São Paulo a motivação para criação foram $50 \%$ $(n=9)$ hobby, 27,78\% ( $n=5)$ negócio, 11,12\% ( $n=2)$ herança, 5,55\% $(n=1)$ por um menor investimento e 5,55\% $(n=1)$ pela diversificação de espécies. Conclui-se que na concepção dos entrevistados a ovinocultura é uma das atividades agropecuárias mais rentáveis, justificada pela intenção da grande maioria em permanecer e crescer na atividade.
\end{abstract}

RESUMO

PALAVRAS-CHAVE: agronegócio, cadeia produtiva.Rentabilidade.

\section{OVINOCULTURA IS A GOOD BUSINESS?}

\begin{abstract}
The objective was to present a sheep and its potential for the producers' vision. It was held during the 58th ExpoLondrina, with people on sheep production in the state of Paraná and São Paulo. Quantitative data were collected on the herd, motivation to begin breeding, participation in events, prospects of the activity. Among the interviewed properties, $51.43 \%(n=18)$ were in the state of São Paulo and $48.57 \%$
\end{abstract}


( $n=17$ ) in Paraná. Most of the animals do not offer any fitness events for genetics and meat, since in relation to the monetization of the two areas they are at the apex of creation. In relation to the motivation to start the creation, such as the correspondences between business, hobby, less investment, heritage and diversification of species in the property. In the state of Paraná, $41.18 \%(n=7)$ created by business, $29.41 \%(n=5)$ for hobby, $17.65 \%(n=3)$ for inheritance, $5.88 \%$ for having a lower investment and $5.88 \%(n=1)$ for species diversification. In São Paulo, the motivation for creation was 50\% $(n=9)$ hobby, $27.78 \%(n=5)$ business, $11.12 \%(n=2)$ inheritance, $5.55 \%)$ for a smaller investment and $5.55 \%(n=1)$ for species diversification. It is concluded that the interviewees' conception is a sheep farming that is one of the most profitable agricultural activities, justified by the intention to increase the duration and the activity in the activity.

KEYWORDS: Profitability, agribusiness, production chain.

\section{INTRODUÇÃO}

No Brasil a ovinocultura é uma importante atividade, muitas vezes de subsistência, sua produção se estende por todo o território nacional, apesar de ser uma atividade visada em pequenas propriedades ela possui uma cadeia da carne bem complexa, dessa forma não se deve apenas discorrer sobre o mercado de forma solitária, é necessário entender como produzir e para quem produzir (ALVES et al., 2014).

A produção de ovinos auxilia na diversificação de tarefas realizadas na propriedade, consequentemente aumentando a produtividade e lucratividade. Nesse caso, um dos grandes gargalos do comércio está no consumo de carne ovina, que ainda é limitado em comparação a carnes de outros animais. Esse fator não é apenas um problema estatal, mas é um desafio da ovinocultura nacional e mundial, principalmente em grandes centros mundiais (ALVES et al., 2014).

Dados de pesquisas do Instituto Brasileiro de Geografia e Estatística, tem-se a informação de que em 2017 o número total do rebanho ovino brasileiro era de 17.976.367 cabeças (LUCENA et al., 2018). Como o Brasil é um país que importa carne ovina de outros países, isso indica que é um mercado em expansão, principalmente nas regiões Centro-Oeste e Sudeste do Brasil.

Essas regiões possuem custo de terras elevado, o que exige uma intensificação da produção para encurtar o ciclo produtivo e viabilizar o negócio, o que muitas vezes leva o produtor a buscar alternativas como o confinamento com resíduos e subprodutos da indústria alimentícia, para que obtenha maior rendimento de carcaça, animais com uma precocidade maior, entre outros fatores (LUCENA et al., 2018).

O consumo anual per capita de carne ovina no país está em torno de 700 gramas, que comparada as demais carnes é baixa, por exemplo, o consumo anual per capita de carne bovina é de $39 \mathrm{~kg}$, carne de frango 44,5 kg e carne suína $13 \mathrm{~kg}$ (ALVES et al., 2014). Assim como no Brasil onde o consumo de carne ovina é baixo, a média mundial de consumo de carne não passa de $2 \mathrm{~kg}$ per capita ano (FAO, 2015), isso se deve a renda familiar, hábito cultural e a baixa oferta do produto no mercado. Com todos esses fatores que interferem na criação de ovinos, o presente trabalho teve como objetivo apresentar informações a respeito da ovinocultura e suas potencialidades pela visão dos produtores. 


\section{MATERIAIS E MÉTODOS}

Durante o evento denominado Expo Londrina, uma das maiores feiras agropecuárias do Brasil na $58^{a}$ edição, que ocorre anualmente no município de Londrina-PR, foi possível realizar entrevistas com pessoas ligadas à ovinocultura no ano de 2018, principalmente criadores e tratadores provenientes de São Paulo e do Paraná. Foi possível entrevistar responsáveis por 35 propriedades criadoras de ovinos, aproximadamente $50 \%$ presentes no evento. Entretanto, representaram $80 \%$ do total de ovinos expostos na feira.

Para as entrevistas foi utilizado questionário próprio (Figura 1), que buscou informações à respeito da logística da propriedade, ou seja, dados quantitativos do rebanho, além de respostas sobre a motivação para início de criação e a participação em eventos, como também opiniões relacionadas à ovinocultura na atualidade e futuramente a respeito do abate de animais, consumo de carne ovina e custo de produção. As entrevistas foram realizadas por estudantes do Mestrado em Saúde e Produção Animal, da Universidade Pitágoras Unopar situada no município de Arapongas-PR.

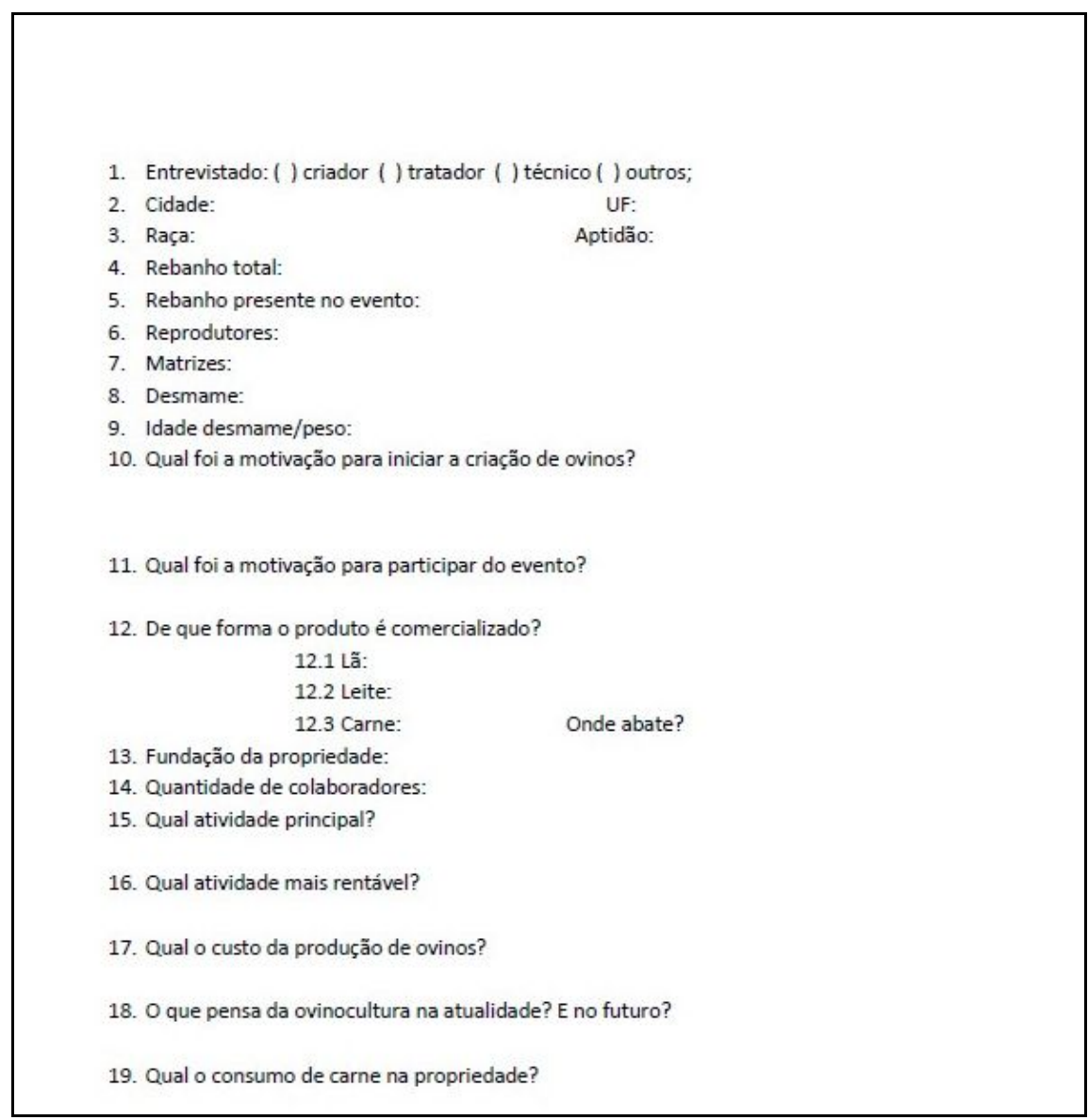

FIGURA 1 - Questionário para realização das entrevistas. Fonte: os autores, 2018.

\section{RESULTADOS E DISCUSSÃO}

Toda a análise que segue está baseada nos dados coletados com as entrevistas. Quando se diz os animais presentes no evento deve-se entender que se tratam dos animais das propriedades entrevistadas. 
Entre as propriedades entrevistadas, $51,43 \%(n=18)$ situavam-se no estado de São Paulo e 48,57\% ( $n=17)$ no Paraná. Dos entrevistados, cerca de $54,27 \%$ $(n=19)$ eram os próprios criadores, $37,15 \%(n=13)$ eram tratadores e $8,58(n=3)$ eram outros colaboradores, como motoristas que transportavam os animais e técnicos das propriedades. Das propriedades do estado do Paraná, a maioria foram os próprios criadores contabilizando cerca de $70,58 \%(n=12)$, além dos tratadores contabilizando cerca de $23,53 \%(n=4)$ e demais colaboradores, sendo $5,88 \%(n=1)$ dos submetidos a entrevista. Já os entrevistados oriundos do estado de São Paulo, na maioria das vezes foram os tratadores, contabilizando cerca de $50 \%(n=9)$, $38,88 \%(n=7)$ eram criadores e $11,11 \%(n=2)$ eram outros colaboradores.

Os animais presentes no evento em sua maioria possuíam aptidão para melhoramento genético e produção de carne, sendo animais da raça Dorper, White Dorper, Texel, Ile de France, Pool Dorset, Santa Inês e Suffolk, visto que com base nas respostas dos entrevistados em relação à rentabilidade estas duas áreas de comercialização estão em ápice na criação.

O rebanho ovino das propriedades que estavam presentes no evento, quantificou-se cerca de 13,557 cabeças, sendo $50,58 \%(n=6.857)$ oriundos do estado de São Paulo e 49,42\% $(n=6.700)$ do Paraná (Tabela 1).

TABELA 1 - Rebanho total ovino das propriedades entrevistadas presentes na Expo Londrina no ano de 2018.

\begin{tabular}{ccc}
\hline UF & REBANHO TOTAL & $\%$ \\
\hline SP & 6857 & 50,58 \\
PR & 6700 & 49,42 \\
\hline TOTAL & $\mathbf{1 3 , 5 5 7}$ & $\mathbf{1 0 0}$ \\
\hline
\end{tabular}

A maioria dos animais presentes no rebanho destas propriedades eram matrizes, totalizando $72,93 \%(n=8.139)$, em seguida animais na fase de desmame totalizando $18,44 \%(n=2.058)$ e por fim os reprodutores que totalizaram cerca de $8,63 \%(\mathrm{n}=963)$ do rebanho (Tabela 2$)$.

TABELA 2 - Número de ovinos por categoria animal de acordo com a classificação estabelecida em questionário de entrevista ocorrida na Expo Londrina de 2018.

\begin{tabular}{lcccccc}
\hline UF & REPRODUTORES & $\%$ & MATRIZES & $\%$ & DESMAME & $\%$ \\
\hline PR & 552 & 57,32 & 4.135 & 50,80 & 1.445 & 70,21 \\
SP & 411 & 42,68 & 4.004 & 49,20 & 613 & 29,79 \\
\hline TOTAL & $\mathbf{9 6 3}$ & $\mathbf{1 0 0}$ & $\mathbf{8 . 1 3 9}$ & $\mathbf{1 0 0}$ & $\mathbf{2 . 0 5 8}$ & $\mathbf{1 0 0}$ \\
\hline
\end{tabular}

Para participar da Exposição, a maioria dos animais eram oriundos do estado de São Paulo totalizando cerca de $61,37 \%(n=448)$, em seguida animais do estado do Paraná quantificando cerca de $38,63 \%(n=282)$ como consta na Tabela 3. 
TABELA 3 - Número de ovinos presentes na Expo Londrina de 2018, das propriedades entrevistadas.

\begin{tabular}{ccc}
\hline UF & PRESENTES NO EVENTO & $\%$ \\
\hline PR & 282 & 38,63 \\
SP & 448 & 61,37 \\
\hline TOTAL & $\mathbf{7 3 0}$ & $\mathbf{1 0 0}$
\end{tabular}

O rebanho dos animais expostos é composto por $70,03 \%$ de matrizes, isso se deve ao fato de que a fêmea é mais dócil, possui um constante manejo e estão mais adaptadas ao manejo de pessoas, além disso, também foi observado que em $53,66 \%$ das propriedades que trouxeram animais para a exposição os donos dos animais estavam presentes no evento, o que mostra uma preocupação com os animais e o bem estar destes durante a exposição.

Entre os expositores a maior parte desmama os animais entre 70 a 90 dias, o que é recomendado. Ávila et al. (2018) observaram que cordeiros desmamados aos 70 dias obtiveram um ganho de peso superior nos machos em relação às fêmeas e o sistema de terminação dos cordeiros com as mães em pastagem nativa foi superior aos que receberam suplementação de $1 \%$ de peso vivo ao dia e os separados das mães em campo nativo.

Zundt et al. (2014) trabalhando com cordeiros mestiços da raça Dorper com suplementação (creep feeding) de ração peletizada até a desmama, só conseguiram o peso ideal para abate aos 80 dias, corroborando com o período de desmame entre 70 e 90 dias. No estudo de Oliveira et al. (2014) houve efeito linear crescente $(P<0,05)$ da idade de desmame sobre o intervalo entre partos. Dessa forma, à medida que se prolongou a idade de desmame das crias, aumentou o intervalo entre partos, minimizando o desempenho reprodutivo das ovelhas.

Com base nas respostas estabelecidas, foi possível realizar uma média de peso ao desmame dos dois estados e com quantos dias estes animais eram desmamados. Possibilitou-se então afirmar que dentre as propriedades que participaram da pesquisa a média de tempo e peso ao desmame no estado do Paraná foi de 93,82 dias com $30,12 \mathrm{~kg}$ e no estado de São Paulo se desmama com 79,16 dias com 29,31 kg.

Em relação à motivação para iniciar a criação de ovinos, as respostas variaram entre os seguintes propósitos: negócio, hobby, menor investimento, herança e diversificação de espécies na propriedade.

No estado do Paraná cerca de $41,18 \%(n=7)$ criavam por negócio, $29,41 \%$ $(n=5)$ por hobby, $17,65 \%(n=3)$ por herança, $5,88 \%(n=1)$ por ter um menor custo no investimento e $5,88 \%(n=1)$ pela diversificação de espécie na propriedade. Já no estado de São Paulo a motivação para criação foram $50 \%$ ( $n=9)$ por hobby, 27,78\% $(n=5)$ por negócio, $11,12 \%(n=2)$ por herança, $5,55 \%(n=1)$ por ter um menor investimento e 5,55\% $(n=1)$ pela diversificação de espécies na propriedade, como consta na Tabela 4.

TABELA 4 - Porcentagem equivalente às respostas dos entrevistados na Expo Londrina sobre a motivação para iniciar a criação de ovinos, 2018.

\begin{tabular}{cccccc}
\hline UF & $\begin{array}{c}\text { Negócio } \\
(\%)\end{array}$ & $\begin{array}{c}\text { Hobby } \\
(\%)\end{array}$ & $\begin{array}{c}\text { Herança } \\
(\%)\end{array}$ & $\begin{array}{c}\text { Menor } \\
\text { investimento (\%) }\end{array}$ & $\begin{array}{c}\text { Diversificação } \\
\text { de Espécie (\%) }\end{array}$ \\
\hline PR & 41,18 & 29,41 & 17,65 & 5,88 & 5,88 \\
SP & 27,78 & 50 & 11,12 & 5,55 & 5,55 \\
\hline
\end{tabular}

Fonte: os autores. 
A motivação para participação no evento variou de marketing, competição e negócio. No estado do Paraná as motivações para estar presente no evento foram $76,47 \%(n=13)$ marketing, $17,65 \%(n=3)$ por negócio e $5,88 \%(n=1)$ por gostar de participar de competições; Já no estado de São Paulo, 38,89\% por gostar de participar de competições, 33,33\% ( $n=6)$ por marketing e 27,78\% $(n=5)$ por negócio.

Em relação a introdução da ovinocultura na propriedade, em propriedades do estado do Paraná variaram sua fundação desde 1978 à 2017, já em propriedades situadas no estado de São Paulo o início da fundação variou de 1973 à 2011.

$\mathrm{Na}$ ovinocultura não se necessita de um número excessivo de mão de obra, uma vez que, os números de colaboradores com base nas respostas dos entrevistados foram em média 3 colaboradores por propriedade. Além disso, a atividade principal nas propriedades do Paraná foi a ovinocultura $(47,06 \%)$ e em seguida a agricultura $(23,54 \%)$, avicultura $(11,76 \%)$, bovinocultura $(11,76 \%)$ e indústria (5,88\%). Resultados semelhantes quando comparados às propriedades do estado de São Paulo onde a ovinocultura lidera com $63,16 \%$ como atividade principal seguida da agricultura $(26,31 \%)$ e bovinocultura $(10,53)$.

Em relação à rentabilidade, encontrou-se a avicultura (17,65\%) como atividade mais rentável no Paraná, seguida da ovinocultura $(11,76 \%)$, agricultura $(11,76 \%)$, e indústria $(5,88 \%)$. Diferentemente das respostas obtidas pelos entrevistados de São Paulo, a ovinocultura lidera como atividade mais rentável $(26,32 \%)$, seguida da agricultura $(21,05 \%)$ e bovinocultura $(5,26 \%)$.

Houveram questões estabelecidas a respeito do custo de produção destes animais mensalmente. As propriedades presentes no evento, apresentaram uma média do custo de produção por estado, o custo no estado do Paraná foi de $\mathrm{R} \$$ 1829,09 e em São Paulo R\$ 1366,76 por animal de valor genético agregado.

Em estudo realizado por Holanda Filho et al. (2018) com ovinos da raça Morada Nova criados extensivamente em propriedades de subsistência no Nordeste, observaram que há um custo total de produção muito menor, de $\mathrm{R} \$ 491,98$ mensal, representando 4,5 vezes menor que o descrito nas entrevistas. Ocorre esta diferença pelo fato dos animais presentes no evento apresentarem um sistema de produção mais intensivo, o que gera custos de alimentação e mão de obra. Além do fato dos animais serem controlados pela Associação Brasileira de Criadores de ovinos, havendo o aumento dos custos. A participação em eventos, como feiras agropecuárias é uma importante ferramenta de marketing, entretanto também aumentam os custos de produção.

Todos os entrevistados no presente evento, apresentaram a mesma opinião quando discutida a prática da ovinocultura na atualidade e futuramente, uma vez que é necessário maior investimento da cadeia produtiva, principalmente na criação de plantas frigoríficas, e que feito isto, a tendência da criação é aumentar cada vez mais, aumentando a oferta e a qualidade do produto.

Em relação ao abate de animais, cerca de $63,41 \%(n=26)$ das propriedades realizam o abate informal, sendo $70,59 \%(n=12)$ no estado do Paraná, $66,67 \%$ e $(n=12)$ no estado de São Paulo e $33,33 \%(n=2)$. O restante das propriedades abatem seus animais em abatedouros, ou seja, $31,71 \%(n=13)$ encaminham os animais para o abate oficial e cerca de $4,88 \%(n=2)$ não realizam nenhum tipo de abate.

Apesar de ter espaço para crescer no mercado consumidor, o abate ainda é um problema na produção, pois o volume de abate formal de ovinos duplicou no período de 2002 a 2007, revelando um crescimento firme e consistente do mercado doméstico. Apesar disso alguns estudos apontam à predominância do abate de 
forma informal que supera a marca de $90 \%$ do total de abates, não sendo detectados pelas estatísticas oficiais, mascarando os dados referentes à comercialização e consumo efetivos desses produtos, além de elevar de maneira significativa a capacidade ociosa dos abatedouros, tornando os empreendimentos deficitários (ALVES et al., 2014). Esses dados também são vistos entre os expositores, $63,41 \%$ dos abates ainda ocorrem em suas propriedades para consumo próprio e comercialização da carne nas proximidades às propriedades.

Com base nas respostas estabelecidas pelos entrevistados foi possível realizar uma média do consumo de carne ovina anual e consequentemente mensalmente, totalizando cerca de 2,702kg/pessoa/ano, ou seja, 0,225 kg/pessoa/mês no estado do Paraná, 3,770 kg/pessoa/ano, ou seja, 0,314kg/pessoa/mês no estado de São Paulo.

No Brasil as importações de carne ovina, em sua maioria procedente do Uruguai, apresentam crescimento regular e firme desde 2004, apesar do aumento de preço ocorrido no mesmo período o que indica um crescimento no consumo de carne ovina (NOGUEIRA FILHO, 2010). Apesar do Brasil comprar carne de ovinos do Uruguai, o consumo de carne ovina é considerado muito baixo. O consumo anual per capita de carne ovina no país é em torno de 700 gramas, comparada as demais carnes é baixa, o consumo anual per capita é de $39 \mathrm{~kg}$ de carne bovina, 44,5 kg carne de frango e $13 \mathrm{~kg}$ carne suína, (ALVES et al., 2014).

Comparando o consumo entre carnes e as exportações é uma atividade que possui espaço para crescer, apesar do consumo per capita do país ser baixo, o consumo de carne entre os criadores é de 2,702kg/pessoa/ano, o que chega a ser quatro vezes mais do que o consumo per capita ano para cada pessoa no Brasil, isso indica que além de espaço para crescer, o consumo está muito próximo dos centros produtores, o que é um problema, por que as regiões que mais consomem carne ovina não são as regiões que mais produzem ovinos.

Diante do exposto pode-se verificar que na concepção dos entrevistados a ovinocultura é uma das atividades agropecuárias mais rentáveis, sendo que na maioria das propriedades é a atividade principal e teve no hobby e na comercialização o início da criação.

O consumo de carne ovina das pessoas ligadas a atividade embora represente quatro vezes o consumo per capita nacional ainda é baixo, sendo que o principal gargalo da atividade apontado é a falta de investimento em plantas frigoríficas resultando no abate informal na grande maioria das propriedades analisadas. A participação em eventos agropecuários é fundamental para o marketing e negócios além da competição entre os produtores, balizando em que fase se encontra o criatório diante dos contemporâneos.

O melhoramento genético e a produção de carne são os aspectos mais importantes das propriedades entrevistadas com um custo de produção de reprodutores e matrizes na ordem de $R \$ 2.200,00$, ou seja, $U \$ 575,00$, com desmame dos cordeiros de 70 a 90 dias e aproximadamente $30 \mathrm{~kg}$ de peso vivo.

\section{CONCLUSÃO}

Conclui-se que na concepção dos entrevistados a ovinocultura é uma das atividades agropecuárias mais rentáveis, justificada pela intenção da grande maioria em permanecer e crescer na atividade. 


\section{REFERÊNCIAS}

ALVES, L. G. C., OSÓRIO, J. C. S., FERNANDES, A. R. M., RICARDO, H. A., CUNHA, C. M. Produção de carne ovina com foco no consumidor. Enciclópédia Biosfera, v.10, n.18, p.2399, 2014. Disponível em: http://www.conhecer.org.br/enciclop/2014a/AGRARIAS/producao\%20de\%20carne.p $\mathrm{pd}$.

ÁVILA, C.J.C., OSÓRIO, J.C.S., OSÓRIO, M.T.M., GONÇALVES, M.S., KESSLER, J.D., KRONING, A.B., PEREIRA, J.R., FERREIRA, O.G.L. Crescimento e desenvolvimento dos componentes corporais de cordeiros Texel x Corriedale machos e fêmeas em diferentes sistemas de terminação. Revista Eletrônica de Veterinária, v.19, n.2, p.1-11, 2018. Disponível em: http://www.veterinaria.org/revistas/redvet/n020218/021801.pdf

FAO, Organização das Nações Unidas para a Agricultura e Alimentação. Meat and Meat Products: price and trade update, 2015. Disponível em: http://www.fao.org/ag/againfo/themes/en/meat/background.html. Acesso em: 20 de mar, 2019.

HOLANDA FILHO, Z.F., MARTINS, E.C., GUIMARÃES, V.P. Custo de produção de ovinos da raça Morada Nova em sistema de produção extensivo no município de Morada Nova-CE. Embrapa, 2018. Disponível em: https://ainfo.cnptia.embrapa.br/digital/bitstream/item/190182/1/CNPC-2018Cot175.pdf

LUCENA, C.C., MAGALHÃES, K.A., MARTINS, E.C., HOLANDA FILHO, Z.F. Pesquisa Pecuária Municipal 2017: efetivo dos rebanhos caprinos e ovinos. Boletim do Centro de Inteligência e Mercado de Caprinos e Ovinos, 2018. Disponível em: https://www.infoteca.cnptia.embrapa.br/infoteca/bitstream/doc/1098631/1/CNPC2018 BCIMn52018.pdf.

NOGUEIRA FILHO, A. N. F. Mercado de carne, leite e pele de caprinos e ovinos no Nordeste. Banco do Nordeste do Brasil, 2010. Disponível em: https://www.bnb.gov.br/projwebren/exec/livropdf.aspx?cd_livro=159.

OLIVEIRA, P.A., CIRNE, L.G.A., ALMEIDA, D.C., OLIVEIRA, G.J.C., JAEGER, S.M.P.L., STRADA, A.R., BAGALDO, A.R., OLIVEIRA, R.L. Desempenho reprodutivo de ovelhas mestiças da raça Santa Inês em Brachiaria humidícula e efeito do sexo no ganho de peso de cordeiros. Arquivos Brasileiros de Medicina Veterinária e Zootecnia, v.66, n.1, p.85-92, 2014. Disponível em: http://www.scielo.br/pdf/abmvz/v66n1/v66n1a13.pdf.

ZUNDT, M., OLIVEIRA, K,P., AMBIEL, A.C., GRECCO, F.C.A.R., CASTILHO,C., FIRETTI, R. Desempenho de cordeiros mestiços Dorper machos e fêmeas, em creep feeding recebendo ração peletizada até a desmama. Colloquium Agrariae, v.10, n.1, p.26-32, $2014 . \quad$ Disponível em: https://www.researchgate.net/publication/284484514.DOI:10.5747/ca.2014.v10.n1.a0 97. 